\title{
What's the best management style for your office?
}

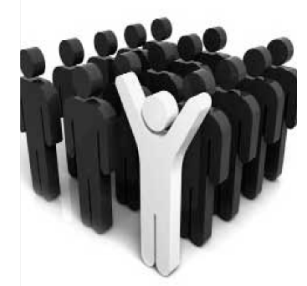

\author{
Edmond BINHAS
}

ABSTRACT

\section{Stating the problem and its ramifications}

The rapid changes that have affected the practice of orthodontics in recent years make it necessary for us to re-examine the traditional ways we have managed our offices. Our basic training, essentially technical in nature, never prepared us to direct the operation of an enterprise that has important business as well as orthodontic treatment components. In today's world we should properly consider our practices as veritable full scale health care delivery organizations. The accelerating rate of change in modern medicine and in the way both patients and referring dentists perceive it and the exponentially rising flood of information about business administration, finance, and law, have all contributed to the block of time that orthodontic offices must devote to management concerns. These details must be dealt with appropriately to allow orthodontists to practice their profession under optimal conditions. And among those essential non-clinical tasks, there is little doubt that proper direction of human resources is the most difficult. And that is entirely understandable because in serving as team leaders orthodontists must interact with a host of individual personality issues. This new challenge is monumental. To confront it successfully orthodontists must become more than skilled technicians, they must perform as successful managers. In this article we propose to present practical rules for efficient office management.

\section{KEYWORDS \\ Management \\ Human resources \\ Recruiting \\ Motivation \\ Team.}




\section{1 - INTRODUCTION}

It is difficult in a single article to summarize a theme whose every aspect has been minutely examined in scholarly tomes. That is why we intend to limit ourselves in this presentation to highlighting the key

\section{2 - WHAT MANAGEMENT STYLE IS BEST?}

Workers in orthodontic offices are subjected to continual stress. And unless orthodontists and their staffs have confidence in each other conditions would soon become impossible for everyone. Worse still, patients would feel the unhealthy emanations! And we should not forget that patients represent not just themselves but also the dentists that have referred them.

That is why one of the major tasks modern orthodontists must assume is creation of team spirit. Consciously or unconsciously assistants in today's orthodontic offices feel a need to fulfill themselves, to blossom out, and to do something worthwhile that will give meaning to their lives and help them rise above the daily humdrum routine.

Orthodontic offices have characteristics that are specific to them and not found in other enterprises. It would not be an exaggeration to assert that managing an orthodontic practice is actually more difficult than directing a much larger organization. Contributing to the strain and the management complications are the requirement for relationships to be maintained in close quarters, and the relatively diminutive over-all size of the working space, the need to work within financial constraints, and the individual points in the management of an orthodontic team. We plan to stress the concepts that we consider to be the most important and not to treat certain others and for this we beg the reader's indulgence.

emotional characteristics of all team players.

Another element specific to orthodontic practice is the practitioners' being forced to play critical roles that have little connection with the training they received as care givers. They can no longer confine themselves to being technicians of orthodontics. They must simultaneously perform as CEOs, administrators, accountants, managers, leaders, and public relations specialists. If we add to that the necessity of keeping abreast of scientific progress through reading journals, attending meetings, and participating in continuing education we can see the extent of the problem orthodontists now have in achieving excellence in every aspect of their professional domain.

\section{2 - 1 - Principle $\mathrm{n}^{\circ}$ 1: Accepting the dual role of Leader and of Manager:}

The first thing to take into account is the distinction between Leader and Manager. Different skills are needed for each function. In most orthodontic offices, although not all, one practitioner must play both roles. To get a better idea of the difficulties involved in 
keeping the distinctions clear let us examine what John Kotter and Abraham Zaleznik ${ }^{3}$, who teach at the Harvard Business School have to say. They have identified the specific competences needed to fulfill each role. We have arranged the differences they specified schematically in this table I.

\section{2 - 1 - 1 - Leader}

In order to reach maximum effectiveness as the orthodontist heading an office staff, we have initially, by a synthetic method, selected the three key points that define good Leadership.

\section{- Ability to accept new roles}

The nature of present day practice requires orthodontists to be competent in both administration and management. Rather than denying this reality, as some practitioners comfortably adjusted to familiar routine may be tempted to do, we urge our colleagues to accept it and to adapt to it as thoroughly as their individual competence and capability will allow. Failing to make the necessary adjustments will inevitably lead to inter-personal problems for many members of the office staff.

\section{- Putting yourself in a "meta-position"}

Orthodontists need to take a step back and detach themselves from emotional involvement in office procedures. By doing this they will give themselves time to reflect on the what has gone on in the past, to review how well routine procedures coordinated with the office's stated objectives and, where necessary, to put them in a new framework for future action. It is true that the daily rhythm of orthodontic practice may make this difficult. This is all the more reason for orthodontists to embark on an unimpeded critical analysis of their management styles. On a practical level, this requires planning and the setting aside of enough time for adequate reflection on that planning.

\begin{tabular}{|l|l|l|}
\hline & \multicolumn{1}{|c|}{ Leader } & \multicolumn{1}{|c|}{ Manager } \\
\hline $\begin{array}{l}\text { Differences in } \\
\text { aptitude }\end{array}$ & $\begin{array}{l}\text { Defines the broad outlines } \\
\text { Interacts well, inspires enthusiasm } \\
\text { Not too interested in details } \\
\text { Sets high and demanding stan- } \\
\text { dards }\end{array}$ & $\begin{array}{l}\text { Pays attention to detail } \\
\text { Rigorous, oriented } \\
\text { toward achievement } \\
\text { Controlling } \\
\text { Capable of performing } \\
\text { well under pressure }\end{array}$ \\
\hline $\begin{array}{l}\text { Differences in } \\
\text { objectives }\end{array}$ & $\begin{array}{l}\text { Creates procedures for changing } \\
\text { things }\end{array}$ & $\begin{array}{l}\text { Creates procedures for } \\
\text { obtaining reproducible } \\
\text { results }\end{array}$ \\
\hline $\begin{array}{l}\text { Differences in the } \\
\text { way they direct } \\
\text { people to } \\
\text { accomplish things }\end{array}$ & $\begin{array}{l}\text { Defines a vision } \\
\text { Shares that vision } \\
\text { Motivates and inspires } \\
\text { Makes workers feel they belong }\end{array}$ & $\begin{array}{l}\text { Plans } \\
\text { Organizes } \\
\text { Directs } \\
\text { Controls }\end{array}$ \\
\hline
\end{tabular}

Table I 


\section{- Establishing a motivating project}

Without entering into the details of this vast subject, let us remember that the development of a professionally provocative project is one of the most profoundly motivating actions an office team can undertake. By highlighting the fundamental reasons for the staff's existence, such a project can make clear how the daily activities reflect and coordinate with the essential values of the office. This provides a sense of usefulness and fulfillment to the routine tasks the team carries out in a way, in our view, far more effective than any psychological motivating techniques could do. The establishment of a professional project, far from being a utopian fantasy should, instead, be firmly based on a precise methodology:

- establish a vision in the form of a mission statement that will respond to the question, "What do you want to create?" This will serve as a reference point, a mental model of what your office will become in the future.

- formulate a work philosophy: This should respond to the question "Why?" Why are we here? Why are we devoting our best efforts and faith to the office? An answer to this question will be an explanation of the true reasons that motivate our efforts.

- outline precise objectives. After having established a mission statement and a work creed, careful time must be allowed for a definition of the step-wise objectives to be obtained. These should be made in the form of progressive stages on the road to the final attainment of the vision. An objective should be specific, measurable, accessible, realistic, and achievable in a reasonable amount of time.

Once the vision, the work creed, and the objectives have been clarified, the final step is, of course, for the orthodontist as team leader is to communicate them to and share them with the staff. The goal at this point is to assure that the team accepts the project and, more than that, subscribes to your professional values.

\section{2 - 1 - 2 - Manager}

The Manager is the person who formulates the Organizational code and puts it to work in running the office. Many orthodontists believe that effective management is based on psychological motivational techniques or on good communication. Certainly these qualities have an important role to play. However, we are persuaded that most of the problems that arise between staff members are rooted in a malfunctioning of an inadequately stated organizational code not inter-personal disputes. That is why our approach to management of an orthodontic office is primarily based on a clarification of organizational behavior with communication techniques coming next.

Accordingly, we find that regular staff meetings facilitate understanding of our organizational system and prevent conflict from developing. All staff members can be kept fully informed by reading and making entries in a ledger that communicates data and news. Only afterwards do we implement simple communication techniques to complete the organizational framework. 


\section{2 - 2 - Principle $n^{\circ}$ 2: Defining a management style}

All orthodontists have their own ideas on what management consists of. We propose one inspired by "Situational Management", that has been effective for us. The base of this model is formed by the intersection of two parameters that, at first view, seem opposed to each other, organization and relationships.

- The organizational axis stimulates us to give directions, to set up procedural pathways, to aim for the attainment of precise objectives: in this realm we are oriented toward accomplishing tasks and to the results that can be attained.

- The relationship axis provokes us to be sensitive to ambiance, workplace conditions, and to staff's interpersonal relationships: motivation of groups is its primordial element.

Depending upon the extent to which we base our behavior on one or the other of these two preoccupations, we can discern 4 possible styles, a weak or a strong personification of the organizational or the relationship styles (fig. 1).

As you proceed through this rapid presentation of management styles

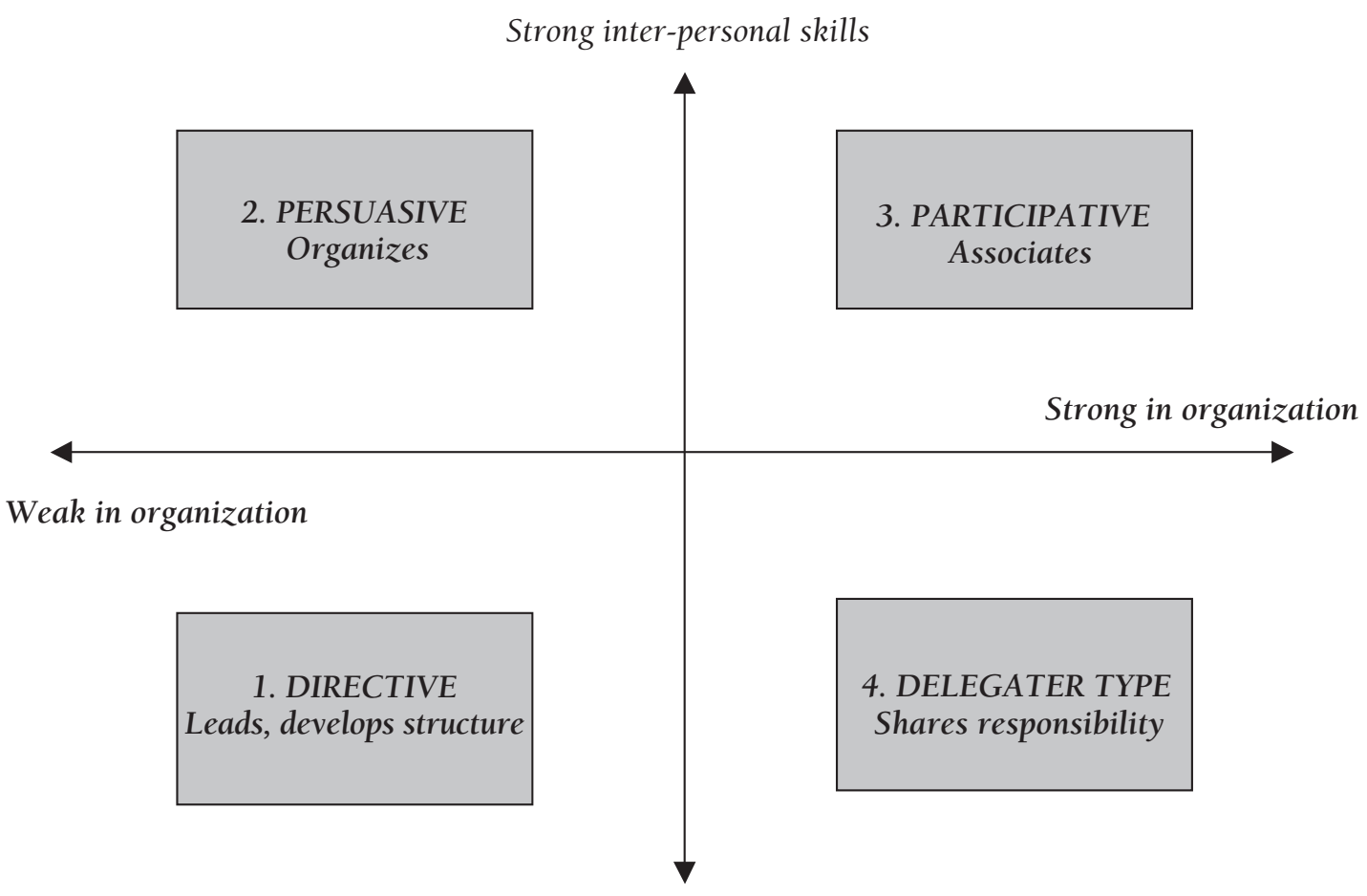

Weak inter-personal skills

Figure 1 
as they are represented in situational management, you can decide where your own inclinations lie on the scale. Do see yourself as having a dominant style? Or do you think you use something from each of the four patterns? If you don't work with all of them, which one, or which ones do you lack? Which element do you deem the most important? Is it completing the task, even at the cost of neglecting the human aspects of the workplace? Or do you emphasize the harmony of the human relationships even if this would impair the quality of the ultimate result?

ATTENTION: the distinction we have made of the four styles is only a rough outline and should not be considered as totally satisfactory. We simply wished to provide a useful guide.

"What are the steps required for putting together an office team?" One of the reasons that mistakes are often made in this process is that orthodontists are too busy. Or, to put it another way, too often the recruiting process drags on over a trail strewn with false trials, errors, and attempted corrections and then winds up with orthodontists dismayed by frequent failures making concessions and hiring people who don't meet the standards that had originally been set.

\section{3 - THE STEPS IN THE FORMATIONOF AN EFFECTIVE TEAM}

\section{3 - 1 - Step 1: Establish an organizational chart that clearly states in writing who will do what}

We should look at the oriental adage "It is written down" and understand it a different way in relation to organization. This means that when things are written down with precision and then printed out and made available, they will provide a base of comprehension for the entire team. That is why we recommend that orthodontists create an Office Manual. A good way to begin is to establish a panoramic view of all the modalities that make up the functions of the office. At first this can be a relatively simple document that can be embellished over time until it becomes a full-fledged working instrument. What should this Office Manual contain?

- A set of House Rules that describes the regulations and functioning of the entire office as well as the individual rights and duties of each staff member.

- Scripts or scenarios for the most frequently encountered communication situations that arise in the office.

- Check lists for technical procedures that need to be accomplished in the office.

- Job Description Manual that describes precisely the purpose, duties, responsibilities, tasks, and relationships of a particular position. This helps the employer decide if the characteristics of a particular candidate are suitable for the particular post. This is a crucial element of the recruiting process. 
- Importance of the Manual and what it contains. Questions it answers:

What is the profile of the position? What are the working hours, functions, and tasks that must be accomplished? The answers to these simple questions help orthodontists to clarify the roles that they want each member of the office team to play. The preparation of written job descriptions for every staff person in an orthodontic office is essential but, unfortunately, it is too often neglected. All too frequently, some offices have no written plans for training and evaluating personnel.

To establish a precise job description orthodontists must first determine the primary and secondary functions of the position and who will be responsible for fulfilling them, what other employees might the holder of this position eventually supervise, how time should be spent and how many overall hours will have to be devoted to the job².

\section{3 - 2 - Stage 2: Recruiting}

\section{3- 2 - 1 - A precondition: accepting the role of employer}

The relationship between an employer and an employee is a contractual one but, more important, it is also a human one. True mutual respect for the pre-established rules, a clear and unimpeded exchange of ideas, and the determination of both parties to fulfill their sides of the commitment are indispensable prerequisites.

An orthodontic office is not a large enterprise; its team often consists of only two people, an orthodontist and an assistant or secretary. This is a professional relationship, of course, but it is also a dyad of two people. And their work exigencies change over time. When the assistant is first employed she may have just have finished her high school or vocational training. Later she may have become a mother with two children! When the orthodontist hired her, he or she may have had children in school. Later these children will have grown up and the orthodontist will have more time to devote to the office!

No matter how legitimate their requirements are, or seem to be, all of the wishes of the parties in this relationship cannot always be granted in the environment of the work place. Frequently, therefore, the work contract must reflect a judicious arbitration between conflicting demands. The contract must be as clear and as precise as possible and must respect the working rights of employees and the overall social contract. And, in spite of all constraints, the contract must have a certain amount of leeway room with support from supplementary associated documents.

Once established, these pre-conditions can become the basis for a fruitful recruiting process.

\section{3 - 2 - 2 - Publication of a positive and motivating advertisement}

This should be designed to attract positive and motivated candidates. We have noted that orthodontists usually publish help wanted ads that are too short and too specific. We recommend, instead, that a recruitment advertisement incorporate these precise characteristics that the candidate should possess: 
- Excellent inter-personal skills.

- Computer competence especially in office software programs for dealing with documents and tables.

- Possession of a high school diploma, or a certificate in training as a medical secretary or dental assistant.

\section{3 - 2 - 3 - The selection process}

In addition, in order to reduce the risk of making mistakes, we suggest the recruiter include three interviews in the selection process. An interview, we believe, is a uniquely rewarding component of the hiring process, well worth the major commitment in time it requires.

\section{- Using the telephone} as a pre-selecting weeding out process

By carefully noting the candidate's tone of voice and enthusiasm on the telephone, the practitioner can identify the individuals best qualified for a follow-up personal interview.

In the face-to-face meeting that ensues the orthodontist should listen $\mathbf{7 0} \%$ of the time and talk $\mathbf{3 0} \%$. In this first encounter, orthodontists should carefully observe the general appearance of the candidates. In addition to what they say, the interviewer should evaluate how they carry themselves. And orthodontists should also pay close attention not just to the content of the interviewee's answers but also to the way in which they are formulated. In other words, orthodontists should be assessing how well the prospective employee is able to communicate. And, finally, orthodontists should look for evidence that the candidate possesses a bright and lively spirit. Personnel in an orthodontic office need to be able to adapt and to react responsibly to emer- gencies. No office manager wants to recruit an employee who will need to have the same things explained over and over again.

- The first rule of hiring. If there's the slightest doubt, don't hire!

If a large number of highly qualified candidates seem to be available, the orthodontist should see each one in a second meeting to talk more specifically about the exact job requirements of the open position.

\section{- The second interview}

At the second interview orthodontists should explain to candidates what kind of practices they maintain. In describing the general outlook of the office and its philosophy they provide applicants with a good idea of what to expect if they are hired. Finally, if an individual appears to possess the appropriate qualifications, the orthodontist should set up a working trial, a technique that is effective for a number of reasons:

- the applicants will have an opportunity to judge exactly what the position consists of,

- if there are other staff members, they will have the opportunity to meet the candidates and to assess their competence and aptitude for integration into the team.

But, of course, it is the orthodontist who should make the final decision.

\section{- The third interview}

The third interview is essentially a meeting in which final commitments can be made, questions answered, and specific points that had been unexplained explicated.

Before making an offer of employment the orthodontist should be certain that the candidate is ready to 
accept it immediately. If the candidate asks for a little more time to think it over, the orthodontist should reconsider the offer because only applicants who really want to join the team should be hired.

So it can be seen that that recruiting a highly qualified and competent person is a long process that requires a considerable amount of time and care. But this time invested is well spent. Sometimes orthodontists who don't want to work without assistance for too long or fear not finding anyone at all hastily engage a dubious candidate who will remain on the job briefly and then depart for greener pastures. We suggest they hire temporary help for a pre-determined intermediate period instead.

\section{3 - 3 - Stage 3: Integration and training}

In order for newly hired staff members to understand fully what their responsibilities will be and for orthodontists to assess the extent of their competence, a period of practical training in the office is usually necessary. Setting aside time for this at the beginning will translate into a gain of time later. In an office with a number of employees, this task can be delegated. The training objective will be to equip the new employee to perform competently as a chair-side assistant, to handle administrative tasks, and to interact successfully with patients and other staff members. No matter what position candidates are expected to fulfill the initial office training should include all three of these components. We strongly recommend that the orthodontist observe how quickly the trainee is able to comprehend the task at hand.
In this vital regard, practical intelligence is often more efficacious that any number of diplomas.

\section{3 - 4 - Stage 4: Delegating intelligently}

Usually it is fairly easy for orthodontists to find tasks to delegate but they must do it correctly and not use delegation as a ploy for mechanically getting rid of unpleasant tasks.

Here are a few considerations that managers should bear in mind in order to achieve efficient delegation:

\section{- Plan delegation carefully, in advance}

List all the tasks that can be delegated, without exception, always, of course, in STRICT compliance with the laws and ethics of good dental practice. (Orthodontists should include all tasks, even if they have time to do them themselves).

The key point is: Delegate ONE complete task to One person.

Other staff members can, of course, assist in completing the job, but the person assigned to it is always RESPONSIBLE for its successful resolution. (Control).

\section{- Clarify the task to be delegated}

To avoid any possible errors, misunderstandings, or minor disputes, it is essential for the manager to communicate clearly. The delegater of the task should focus on results and not on the way they are achieved and should be sure to provide the assignee with enough authority and sufficient means to get the job done. Next the manager should be sure the assignee accepts the responsibility and is convinced of the feasibility of the task's being achieved. Then the manager and the 


\section{Check-list for effective delegation}

Establish a sense of confidence in the office team from the beginning.

Accept the loss of some control.

$\checkmark$ But, in return, expect proof that your confidence is justified.

$\checkmark$ Delegate every time it is possible to do so.

$\checkmark$ Motivate your personnel.

$\checkmark$ Establish clear objectives and spell out the order of their importance.

$\checkmark$ Decide how much lee-way to allow your employees.

$\checkmark$ Share your resources.

$\checkmark$ Check up on the performance of delegated duties.

$\checkmark$ Evaluate progress achieved, encourage workers.

When errors are made, discuss them and explain precisely what needs to be done.

worker should agree on a date for its fulfillment. (Date limit).

\section{- Make frequent checks on the status of the job}

The absence of control of work in progress is one the most frequently encountered errors and is one of the most serious breakdowns in good delegation. Managers should understand that ongoing assessment is an

\section{4 - MAINTAINING DEDICATION}

In our view, managers have an impossibly utopian vision of procedure if they think they can inspire motivation in people who do not already possess an inner spark for it. What happens all too often in many offices is that when a team member accomplishes one task correctly and swiftly, the manager succumbs to the temptation of assigning that person additional work. And when, conversely, another staffer fails integral part of delegation. Managers should encourage team members to fill out a liaison notebook.

As the work progresses, managers should communicate their impressions of how it is going including positive as well as negative feedback. When managers are pleased with the results obtained, they should congratulate the worker and provide appropriate recompense.

to finish a task within the agreed time limit and, worse, does not do it properly, managers tend to take over the job themselves. This type of behavior is counter-productive and, in fact, de-motivates the most dedicated workers. Another classical error is, in deference to a misguided sense of fairness, to give equal bonuses to everyone, which, in fact, favors the poorest performers. 


\section{4 - 1 - So how can motivation be maintained?}

There is no one answer to this question because motivations vary from person to person. Many orthodontists assume that the principal motivating factor is money. However, the great majority of employees believe their salaries are the normal compensation for the work they provide. On the other hand, they consider recognition and praise as appreciation above and beyond the ordinary and would accept additional responsibility or different working hours to receive them.

Peter Drucker ${ }^{1}$, an American expert in management, warns us about the risks that can accompany supplementary financial rewards. Staff members may come to expect regular bonuses, given monthly, or at the end of the year, as their right and, accordingly, interpret the failure to give one as a reprimand.

\section{- Expressing gratitude and thanks}

An expression of appreciation is as we have said, certainly the principal motivating factor for staff members in an orthodontic office. Giving thanks is a powerful tool for motivating personnel and for obtaining their commitment. Here are some practical ways of doing it: offering interesting and desirable tasks, letting everyone know what a good job has been done, offering additional days off, reviewing with staff the excellence of their performance, including team members in decision making processes, organizing congratulatory parties and celebrations, and providing staff with additional responsibilities.

\section{- Communicating effectively}

One of the fundamental principals for maintaining staff interest and motivation is for all team members to COMMUNICATE effectively with each other. The most serious problems are usually those caused by what is not said, or properly communicated. That is the reason for what is probably the most critical rule of all: staff MEETINGS must be held regularly. There are four types of such reunions, each related to different and quite precise objectives:

- The daily meeting, held in a maximum of 10 to 15 minutes, whose objective is to set out the plans for the day and to anticipate how well events will transpire.

- The bi-monthly meeting that should last for one or two hours depending on the number of staff members. The objection of this session is to deal with basic organizational matters such as stock control, training of personnel, new materials and new techniques, and organizational innovations. Timing for vacations and other absences of staff members should also be discussed as well new ways of providing services designed to please patients such as redecorating the office. Setting up games and contests should also be discussed. Another important matter for consideration at this meeting is improving relationships with referring dentists with meetings, study club sessions, luncheons, and other strategies.

- The annual evaluation session when the orthodontist should meet individually with each staff member for 3/4 of an hour to an hour to review the year's performance.

- The improvised meeting that is always face to face with the orthodontist dealing in a brief session with an 
unexpected but urgent problem or tension between employees. These are both matters that need to be resolved immediately.

\section{- Departure of a staff member}

Sometimes an employee has to leave the office or has to be asked to leave. After only a few months of employment or even many years it can become necessary for the worker and the office to continue on their separate paths. Among the onerous tasks that an orthodontist manager is called upon to fulfill, firing an employee is doubtless the most difficult. Not even the most experienced among us ever get comfortable with it. It is the emotional component of the action that is the hardest to endure especially when the orthodontist has worked with the employee over a long period of time.

That is why even veteran employers hesitate to carry out a fully justified dismissal of a staff member. The motives for this indecision are multiple:

- fear of what might happen. Will the employee being dismissed burst into tears or become hysterical?

- dealing with inevitable emotional overlay.

- fear of appearing harsh and ruthless.

- fear of a possible law suit, not an unreasonable worry in jurisdictions where laws tend to favor employees.

- hoping secretly that the problem will somehow go away before there is any need to take action.
How to conduct a dismissal process in three steps:

We suggest that orthodontists adopt a stance of extreme prudence before firing an employee. In today's litigious climate it is imperative that they engage an attorney experienced in social law before making the first move but the worker involved should not be informed of this precaution. That would immediately transform the process into a court case.

We propose the following steps that can help to keep the personal interaction as smooth as possible. They have no judicial value whatsoever. For legal advice orthodontists should consult their attorneys.

Step 1: in a private face to face meeting the orthodontist should inform the employee in clear terms about the dismissal.

Step 2: the orthodontist should clearly explain the reason for the dismissal demonstrating empathy but remaining neutral and firm and under complete control.

Step 3: the orthodontist should indicate the date upon which the dismissal will go into effect and explain the procedure

Despite all the difficulties that accompany it, the firing of an employee is still nothing more than a severance. No matter how painful it may be, it is often a necessary step in the preservation of harmonious office working conditions.

\section{5 - INTER-PERSONAL RELATIONSHIP ASPECTS OF MANAGING AN OFFICE TEAM}

We do not have sufficient space to review all the communication techniques that can be used in an orthodontic office. So we shall limit ourselves to outlining a few simple methods of resolving conflicts. Do not 
be misled by the apparent simplicity or seemingly obvious nature of these techniques. Applied rigorously, they constitute management rules that are remarkably efficacious.

\section{- Four simple techniques for resolving conflicts}

- A preventive technique: Establish then maintain confidence. This is a necessary pre-condition for any motivation technique to make sense. Confidence, of course, implies mutual respect not only between the practitioner and the office team but also of all members of the team with each other. The more numerous the work force is, the more complicated the situation becomes.

- Do not allow important sentiments to be left unsaid. Most often we fail to say what needs to be said because of a lack of time or because we fear how the interlocutor will respond to our statement. It is essential that we dare to speak up when we sense tension is building between two staff members.

- Always deal with the behavior, not the person. It is counter-productive in an interaction to blame, to infantilize, or to devalue the other person. The simplest technique is to point out a fact, emphasizing its tangible aspects, saying, perhaps, "There were no more brackets in the storeroom."

- I have a problem: When you are annoyed or frustrated by someone, you are the one who has a problem. Instead of accusing the other person in terms like these, "You have a problem, you didn't do this or that," we strongly recommend that you begin the discussion in this way, "I have a

\section{Ten classical errors made in managing the staff of an orthodontic office}

As managers, orthodontists, of course, make mistakes. But these errors should be considered as normal parts of the learning process. Here is a list is a list of ten snares that Orthodontist-managers, whether or not they are experienced, may be tripped up by:

1. Not setting aside enough time to spend with the office team

2. Not making the transition between Clinician and Manager

3. Not delegating

4. Not establishing objectives for the team to aim at

5. Not communicating

6. Thinking they already know how to manage

7. Resisting change

8. Not expressing gratitude

9. Not responding promptly to urgent problems

10. Taking themselves too seriously: management is clearly a serious business. However, orthodontic managers should keep their sense of humor and create an agreeable environment for themselves, their staff members, and their patients, especially for the majority of them who are children!!!! 
problem. I was upset because there were no more brackets in stock..."
This immediately defuses the interlocutor's aggressive feelings.

\section{6 - CONCLUSION}

In today's world practitioners will have to assume management roles in order to be sure their orthodontic offices function effectively. In this article we have tried to present the basics of management in a schematic way and also to provide a methodology for the installation of a management style that will not only be more efficient but also more human. These two seemingly disparate elements far from being incompatible can actually become complementary in an age when offices, on the one hand, have to deal with a state of affairs that becomes more and more complex every day, and, on the other hand, where individuals have to deal with insecurity in the work place.

We believe that it is essential for orthodontists to assume control of their offices from a management point of view, a topic not taught in dental schools, with rigor and professionalism. This means that they must reflect profoundly not only on the office's over-all mission but also on precise objectives. Orthodontists should devote constant attention to recruitment, internal communications, staff training, and follow-up evaluation of staff. Motivation of staff never develops accidentally. Members of orthodontic teams need to find some sense of purpose in their daily work and have to understand the utility of what they do. But this can only happen when they enjoy a healthy give and take relationship with the practitioner who is responsible to see that conditions are in place for this to occur.

\section{REFERENCES}

1. Drucker PF. The Practice of Management Harper and Row, Publishers, Inc. New York, 1986.

2. Convention collective des Cabinets Dentaires ( $\left.N^{\circ} 3255\right)$ rubrique «classification des emplois, II-Emplois d'assistant(e) dentaire ", et " classification des emplois, IV- Autres emplois en cabinet dentaire et $\mathrm{V}$ - Travaux de secrétariat», le poste Réceptionnistes Hôtesses d'accueil - Secrétaires. Direction des Journaux Officiels, Service Commande, 26, rue Desaix, 75727 PARIS Cedex 15.

3. Mintzberg H, Kotter JP, Zaleznik A. Harvard Business Review on Leadership, Harvard Business School Press, Boston:1998;9:61-9.

\section{MORE LITTERATUR}

- Rozencweig Daniel. Des clés pour réussir au Cabinet dentaire. Quintessence International Editeur - Paris 1998.

- Catry Claudine et Muller Jean-Louis. Exercez votre autorité avec diplomatie. ESF Editeur - Paris 1998. 
- Georges M. Patrick. Gagner en efficacité en équipe. Editions d'organisation / groupe Eyrolles Paris 2004.

- Mintzberg Henry. Le manager au quotidien. Les 10 rôles du cadre. Editions d'organisation / groupe Eyrolles, Paris 2006.

- Nelson Paul et Economy Peter. Le management pour les Nuls. Sybex Editeur, Paris 1997.

- Schutz Will. L 'élément humain. Interéditions, Dunod, Paris 2006. 